\title{
Strengthened Peening Effect on Metallurgical Bonding Formation in Cold Spray Additive Manufacturing
}

\author{
Yingchun Xie $^{1,2} \cdot$ Chaoyue Chen $^{1,3}$ (I) Marie-Pierre Planche ${ }^{1} \cdot$ Sihao Deng ${ }^{1} \cdot$ \\ Renzhong Huang ${ }^{2}$ Zhongming Ren ${ }^{3} \cdot$ Hanlin Liao ${ }^{1}$
}

Submitted: 29 October 2018/in revised form: 14 January 2019/Published online: 22 March 2019

(C) ASM International 2019

\begin{abstract}
Cold spraying is a solid-state coating process and promising technique for additive manufacturing. However, questions raise about the bonding mechanism between the particles forming the coating. In this study, the strengthened peening effect is proposed as the determining factor for the formation of metallurgical bonding in cold spray additive manufacturing. Ni coatings and single splats were produced on $\mathrm{Al}$ substrates with different propelling gas pressures. Contrary to common understanding, no metallurgical bonding was observed in single-particle impact, even at the pressure of $3.7 \mathrm{MPa}$. However, the metallurgical bonding was observed at the full coating deposition through the existence of diffusion after heat treatment. Thus, the strengthened peening effect of subsequent particles with successive impact energy might be the determining factor for the formation of metallurgical bonding. Actually, strengthened peening effect significantly improved the coating quality through enhanced metallurgical bonding, which was proved by the increasing adhesion strength and decreasing porosity.
\end{abstract}

Chaoyue Chen

cchen1@shu.edu.cn; chaoyuehenry@hotmail.com

1 LERMPS, ICB, UMR 6303, CNRS, Univ. Bourgogne Franche-Comté, UTBM, 90010 Belfort, France

2 National Engineering Laboratory for Modern Materials Surface Engineering Technology, The Key Lab of Guangdong for Modern Surface Engineering Technology, Guangdong Institute of New Materials, Guangzhou 510651, People's Republic of China

3 State Key Laboratory of Advanced Special Steels, School of Materials Science and Engineering, Shanghai University, Shanghai 200444, People's Republic of China
Keywords additive manufacturing · cold spraying · diffusion layer - peening effect - propelling gas pressure

\section{Introduction}

Additive manufacturing (AM) designates a layer-by-layer manufacturing technology of a component with complex geometry (Ref 1, 2). Based on 3D model in CAD files (e.g., stl), objects with complex geometry or shape can be produced. Different from the traditional subtractive manufacturing such as milling and machinery, additive manufacturing can effectively avoid the unnecessary waste in terms of time and cost. In such AM processes, the highenergy sources like laser or electron beam can be used to melt down the powder bed selectively, whereas the resulting solidification can achieve the fabrication. It includes the selective laser melting (SLM) (Ref 2, 3), selective laser sintering (SLS) (Ref 4) and electron beam melting (EBM) (Ref 5). However, for such high-energybased methods, the disadvantages like residual stress and unwanted phase transformations due to high processing temperature cannot be avoided.

As a recently emerged technology, the cold-spraying (CS) technique (Ref 6, 7) can fabricate the sample through the solid-state deposition of feedback powders without melting and solidification. In this process, powders are accelerated to high velocity under the effect of supersonic flow (Ref 8). The successful bonding occurs through the intensive plastic deformation of solid-state particles upon high-velocity impact at a temperature below the melting point (Ref 9-11). Due to the unique 'cold' feature, cold spray can minimize or eliminate the serious oxidation, phase transformations and thermal stress and can be widely applied for the fabrication of functional coatings (Ref 12), 
metallic matrix composites (Ref 13,14), additive manufacturing (Ref 15, 16) and dimensional damage repair (Ref 17).

In order to improve the coating quality, the bonding mechanism is always a hot topic in cold spray (Ref 18, 19). Currently, mechanical (Ref 20-24) and metallurgical bonding ( $\operatorname{Ref} 7,10,25)$ is considered as the main bonding mechanisms in cold spray. At the oxide-free interface and metal-to-metal contact, metallurgical bonding is formed as a chemical reaction between deposited particles or interface between coating and substrate (Ref 26). Metallurgical bonding is considered to provide relatively high adhesion strength in cold-sprayed coating and has been experimentally observed through the evidence of intermetallic, amorphous phases or dimple-like feature at the fracture surface of coating or single splat (Ref 27-29). The most acceptable perspective of the formation mechanism of metallurgical bonding is the rise of adiabatic shear instability (ASI) (Ref 7, 30) resulting from the high strain rate $\left(10^{8}-10^{9} \mathrm{~s}^{-1}\right)$ and the localized plastic deformation at the interface. Due to the adiabatic heating dominant over work hardening at ASI region, the thermal softening causes the metal behaves like viscous material, which leads to the formation of outward jet and extrusion (Ref 7, 20, 30, 31). Thin oxide surface on particle or substrate is disrupted due to the strong plastic deformation during impact, which discontinues the intimate contact between particles and substrate (Ref 23, 32, 33). Generally, dimple-like ductile feature at the fracture surface is considered as the sign of metallurgical bonding (Ref 10, 34, 35). However, most current studies that focus on the cross-sectional observation by SEM, TEM or even FIB method cannot provide adequate information of the bonding situation.

As an effective method to improve material properties, peening effect has been introduced to cold spray coating to intensify plastic deformation and improve densification (Ref 36-38). For example, Luo et al. (Ref 39) applied in situ shot peening by mixing large-sized stainless steel particles with spraying powders to prepare dense Ti6Al4V and commercially pure Ti coatings. The results show that the in situ peening can significantly improve the densification and increase the microhardness through remarkable work hardening. Similarly, Wei et al. (Ref 40) fabricated fully dense Al6061 alloys on AZ31B substrate by deposition of Al6061 powder blended with large-sized stainless steel particles. The results show that the addition of in situ shot-peening particles can notably reduce porosity and improve corrosion resistance. Based on the extra consolidation and compaction of coating microstructure, the pure $\mathrm{Ni}$ coating fabricated by in situ shot-peening cold spray presented strong adhesion strength and corrosion resistance (Ref 41).
Besides the peening effect by mixing large particles in the feedstock powders, the unbonded particles can also produce peening effects on the already formed coatings. In this study, the effects of strengthened peening effect at higher propelling gas pressure on the bonding features between $\mathrm{Ni}$ particle/Al substrate and $\mathrm{Ni}$ coating/Al substrate were investigated to understand the bonding mechanism. Heat treatment was conducted to emphasize the metallurgical bonding through revealing of diffusion zone at direct contact areas. The direct observation of contact surface on the particle detached from the substrate as well as the diffusion zone between coating and substrate was used to investigate the bonding features of $\mathrm{Ni}$ single splat and coating. Therefore, a theoretical reference is provided to improve the bonding strength of the coating fabricated by cold spray.

\section{Experimental Procedures}

Pure nickel powder (ECKA Granules, Germany) with a spherical morphology and a mean diameter of $32 \mu \mathrm{m}$ was used as the feedstock. The SEM morphology and size distribution of the Ni powder are given in Fig. 1. Cylindrical samples of aluminum with a diameter of $25 \mathrm{~mm}$ were used as the substrate for adhesion strength test. $\mathrm{Al}$ substrates that were polished and grit-blasted were prepared, respectively, for deposition of individual splat and full coating. Cold-sprayed coatings and splats were manufactured by a CGT K3000 system at LERMPS, UTBM, France. High-pressure argon was used as powder carrier gas in the powder feeder. Compressed air with a temperature of $600{ }^{\circ} \mathrm{C}$ was used as propelling gas to accelerate powder. The standoff distance between nozzle exit and substrate was set as $30 \mathrm{~mm}$. The pressures of propelling gas of 2.0, 2.4, 2.8 and 3.7 $\mathrm{MPa}$ were used to evaluate its effect on coating properties. The nozzle traverse speeds to manufacture the individual splats and full coatings were 500 and $100 \mathrm{~mm} / \mathrm{s}$, respectively.

The observation of the Ni-Al diffusion layer generated obtained by the heat treatment at fresh metal interfaces was used to directly investigate the bonding features. Coldsprayed coatings were heat-treated with an argon protection in a tube furnace. The samples were heated up to $400{ }^{\circ} \mathrm{C}$, held for $15 \mathrm{~min}$ and then cooled down in a furnace to room temperature. Simultaneously, the bonding features of Ni single splat were studied by directly observing the fractured contact surface detached from the substrate by a tensile tester (IC ESCOFFIER, Estotest 50, France) (Ref $10,26)$. The bonding strength of cold-sprayed coatings was measured using a pull-off test (ASTM C-633-01). The adhesion strengths between the coating and substrate were tested with a crosshead speed of $1.26 \mathrm{~mm} / \mathrm{min}$ using the 
Fig. 1 (a) Morphology and (b) size distribution of $\mathrm{Ni}$ particles

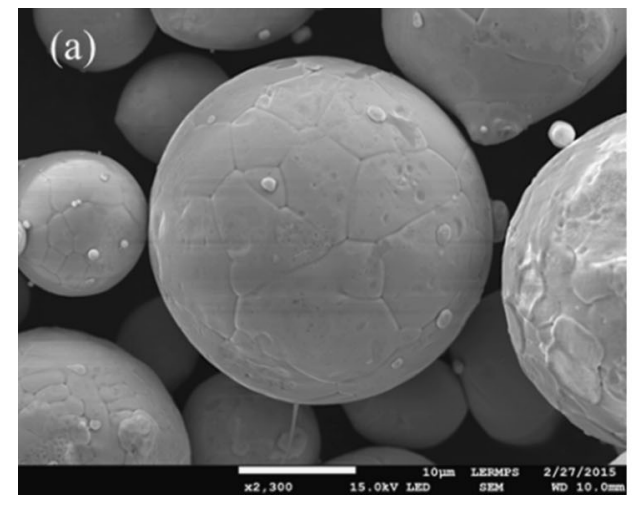

same tensile tester. The microstructures of powder and coatings were analyzed by the scanning electron microscopy (SEM) that is equipped with an energy-dispersive spectroscopy (EDS) unit (JEOL, JSM-5800LV, Japan).

\section{Finite Element Analysis Model}

In this study, a computational fluid dynamics (CFD) model by the commercial code of Fluent was developed. Based on the experimental conditions and the nozzle dimensional, a simplified two-dimensional axisymmetric CFD model was used to predict the velocity and temperature of particle prior to impact onto substrate. Grid of quadrilateral elements was used to mesh the computational domain. Experimental propelling gas pressures (2.0, 2.4 and 2.8 MPa) were tested. Spherical Ni particles with a diameter of $30 \mu \mathrm{m}$ that possess initial velocity and temperature of $25 \mathrm{~m} / \mathrm{s}$ and the $25{ }^{\circ} \mathrm{C}$ were used as injected powders at the nozzle inlet. The details of the CFD model can be referred to the previous work (Ref 42).

Based on the CFD simulation results, the coating buildup process as well as particle deformation behavior was simulated via a commercial explicit code, Abaqus Explicit, with Eulerian algorithm. The dynamic temperature-displacement explicit procedure was used to account the coupled thermal and mechanical process during impact. 3D Eulerian coupled temperature-displacement eight-node element (EC3D8RT) was used to mesh the computational model. The particle with a diameter of $30 \mu \mathrm{m}$ was used in this model to meet the particle size distribution in experiment. For capturing the deformation features and increasing the simulation accuracy, the mesh at the region near particle/substrate interface was refined to $0.2 \mu \mathrm{m}$. The computation domain as well as the meshing is given in Fig. 2. The velocity and temperature of Ni particles were set according to the results of the aforementioned CFD model at different propelling gas pressures.

The Johnson-Cook plasticity model (Ref 43) was used to describe the plastic deformation and heat transfer during cold spray deposition, which accounts the strain hardening, strain rate (viscosity) and thermal softening. The yield stress can be expressed as the equation given below:

$\sigma_{y}=\left[A+B\left(\varepsilon_{e}^{p}\right)^{N}\right]\left[1+C \ln \left(\frac{\dot{\bar{\varepsilon}}^{p l}}{\dot{\varepsilon}_{0}}\right)\right]\left[1-\left(T^{*}\right)^{M}\right]$

where $A, B, N, C$ and $M$ are material-related constants based on the flow stress data obtained from mechanical tests, $\varepsilon_{e}^{p}$ is the effective plastic strain, $\dot{\bar{\varepsilon}}^{p l}$ is the equivalent plastic strain rate and $\dot{\varepsilon}_{0}$ is the reference strain rate. $T^{*}$ is a non-dimensional temperature defined as:

$T^{*} \equiv \begin{cases}0 & \text { for } T<T_{\text {transition }} \\ \left(T-T_{\text {transition }}\right) /\left(\left(T_{\text {melt }}-T_{\text {transition }}\right)\right) & \text { for } T_{\text {transition }} \leq T \leq T_{\text {melt }} \\ 0 & \text { for } T>T_{\text {melt }}\end{cases}$

A linear Mie-Grüneisen equation of state (EOS) was employed to account the material elasticity. Besides, assumption is made here that mechanical and thermal properties of the materials are isotropic. The material properties can be referred to elsewhere (Ref 44,45$)$.

\section{Results}

\section{Bonding Features of Single-Particle Deposition}

The bonding features of the single-particle deposition are given and discussed to investigate the influence of propelling gas pressures on the bonding mechanism of coldsprayed Ni onto Al. Figure 3 shows the surface and the cross-sectional morphology of a single $\mathrm{Ni}$ particle deposited onto $\mathrm{Al}$ substrate at different propelling gas pressures. The deposited particle will possess increasing kinetic energy during impact. It can be observed in Fig. 3 that by increasing the pressure, the $\mathrm{Al}$ substrate was deformed more extensively and a metal jet of substrate around the particle became clearer. In order to understand the metallurgical bonding, the analysis of $\mathrm{Ni}-\mathrm{Al}$ diffusion zone was conducted. Meanwhile, the formation of intermetallic phase after heat treatment is widely recognized as the mark 
Fig. 2 Computational domain and meshing of the particle impact model (a)
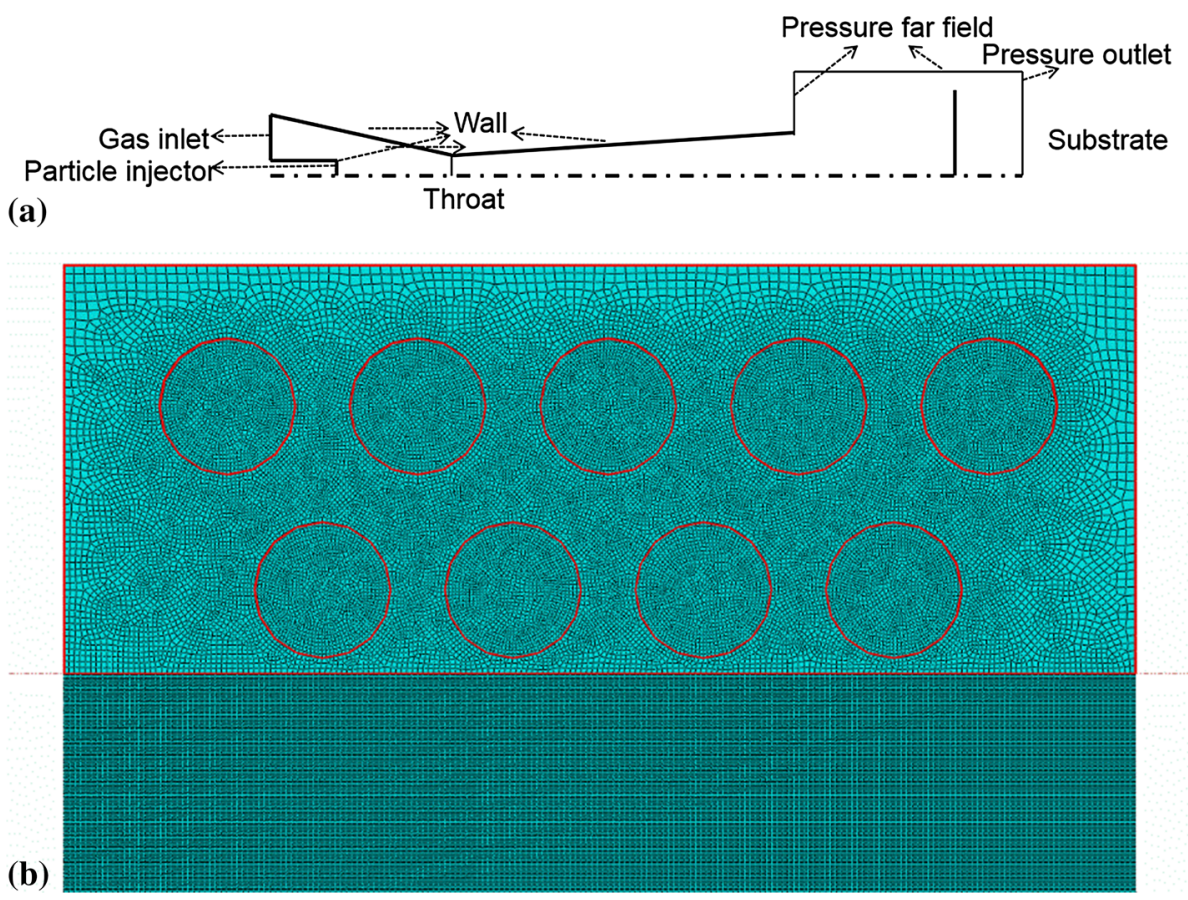
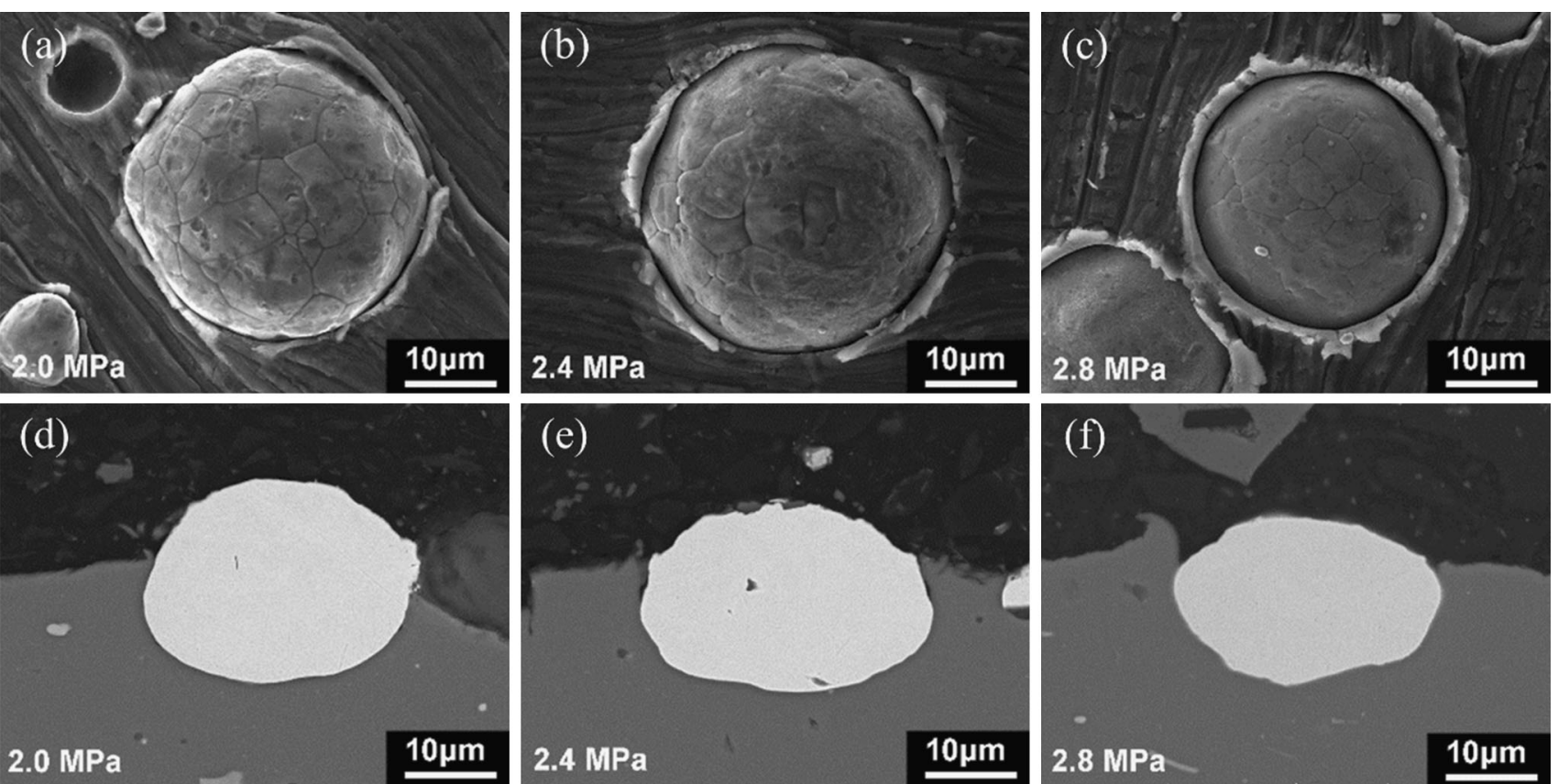

Fig. 3 Morphologies of surface and cross-sectional (after heat treatment) of a single splat at: (a) and (d) $2.0 \mathrm{MPa}$, (b) and (e) $2.4 \mathrm{MPa}$, (c) and (f) $2.8 \mathrm{MPa}$

for fresh metal intimate contact and thus the metallurgical bonding (Ref 46-48). The cross sections of a single splat after heat treatment are given in Fig. 3(d), (e) and (f). The satisfactory bonding interfaces between splats and substrates can be found without pores or oxide film debris after the intense deformation. However, no Ni-Al diffusion zone was generated at the interface between splats and substrates after heat treatment. Furthermore, the deposited particle was detached from the substrate and the bonding interface at the particle was observed directly, which can provide adequate information about the metallurgical bonding behavior. As shown in Fig. 4, the bonding interfaces of the deposited particle at different propelling pressures were observed after detachment from the substrate. The fractured contact surface was clean and without signs of metallurgical bonding. However, according to the previous 

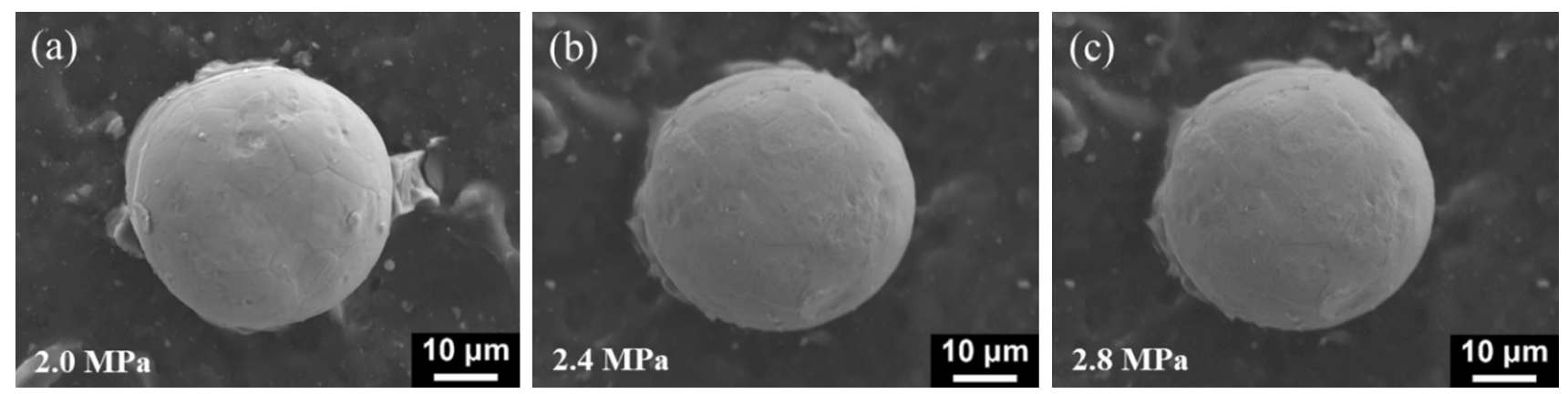

Fig. 4 Bonding interface of the deposited Ni particle at different propelling pressures that was detached from the substrate
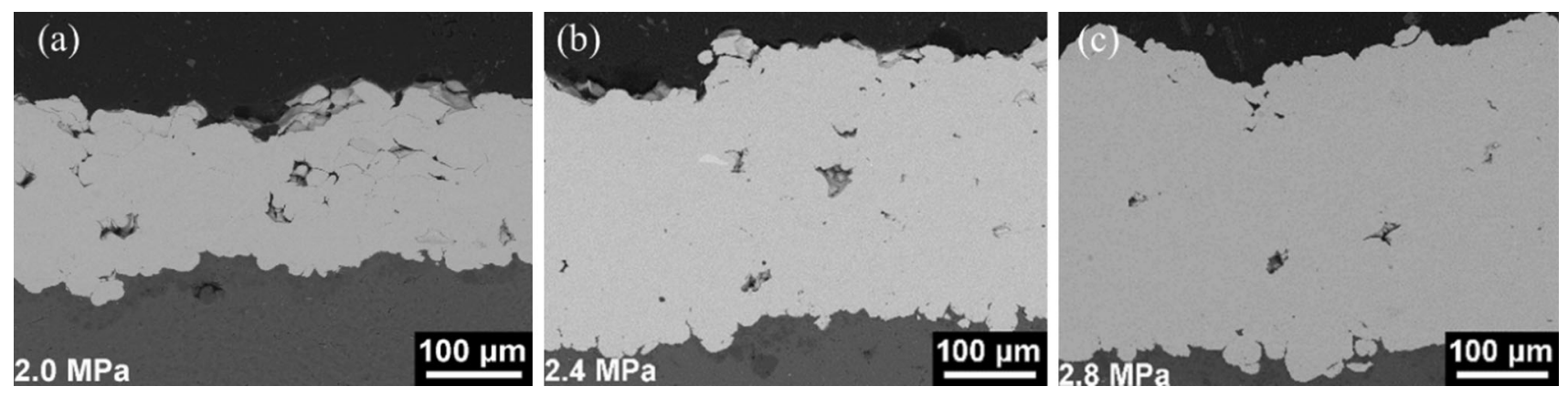

Fig. 5 Cross-sectional morphology of as-sprayed Ni coating at different propelling gas pressures

study on the deposition of single Ni particle onto stainless steel substrate, a ring of dimple-like features that indicates the ductile fracture can be observed at the bonding interface of detached particle (Ref 10). Furthermore, such dimple-like ductile feature at the fracture surface is widely considered as the sign of metallurgical bonding (Ref $10,34,35)$. Thus, based on the absence of interfacial diffusion zone and dimple-like features, it can be concluded that the metallurgical bonding was absent in the case of single particle/substrate, even at relatively high propelling gas pressure.

\section{Bonding Features of Full Coating Deposition}

Contrast to the single-particle deposition, the full $\mathrm{Ni}$ coating deposition onto $\mathrm{Al}$ substrate with distinguishing bonding features is observed and discussed in part. Figure 5 shows the cross-sectional morphology of the $\mathrm{Ni}$ coatings obtained at different propelling gas pressures. It can be noticed that the coating thickness is increasing as a function of the increasing propelling gas pressure. Figure 6 shows the coating porosity as a function of the propelling gas pressure. As expected, it can be found that the coating porosity decreases as a function of the propelling gas pressure. It suggests that the enhanced peening effect at higher propelling gas pressure can promote the plastic deformation of the coating and largely eliminate the

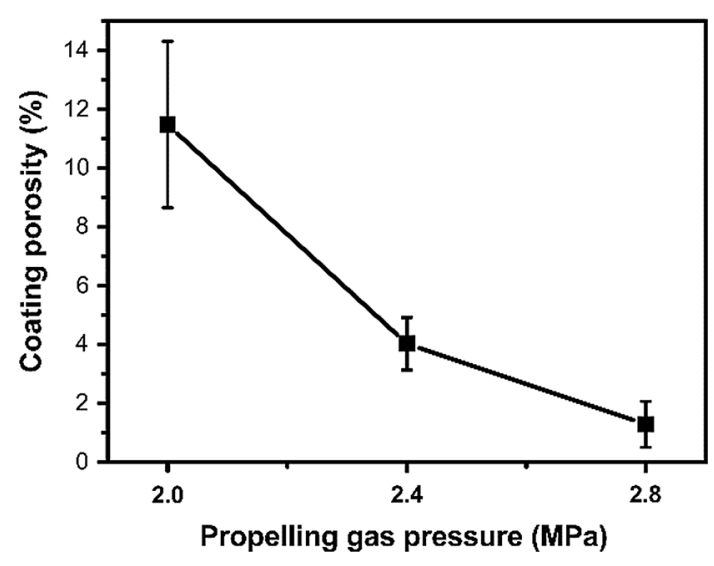

Fig. 6 Coating porosity as a function of propelling gas pressures

apparent gap and pore-like defects in the coating. To further study the interfacial bonding between coating and substrate, the interfacial bonding features of $\mathrm{Ni}$ coating at different propelling gas pressures after heat treatment are shown in Fig. 7. Marked by the white arrows, the Ni-Al diffusion zone at the interface became gradually evident and large as the pressure increases. At the pressure of 2.0 MPa, few diffusion areas can be found along the coating/substrate interface after heat treatment. As for the pressure of $2.8 \mathrm{MPa}$, the Ni-Al diffusion layer has filled most interface regions, which means that a relatively larger 
oxide-free area was exposed allowing the direct metal-tometal contact and a more evident metallurgical bonding.

In order to identify the element mixture at the interface, EDS line scan was made on the full coating fabricated at the pressure of $2.8 \mathrm{MPa}$ and given in Fig. 8. Typical Ni-Al diffusion layer can be seen to be formed by atomic diffusion at the interface between coating and substrate, which was due to intimate contact between fresh metals of $\mathrm{Ni}$ and Al. It is known that the formation of such diffusion zone after heat treatment is able to indicate the formation of
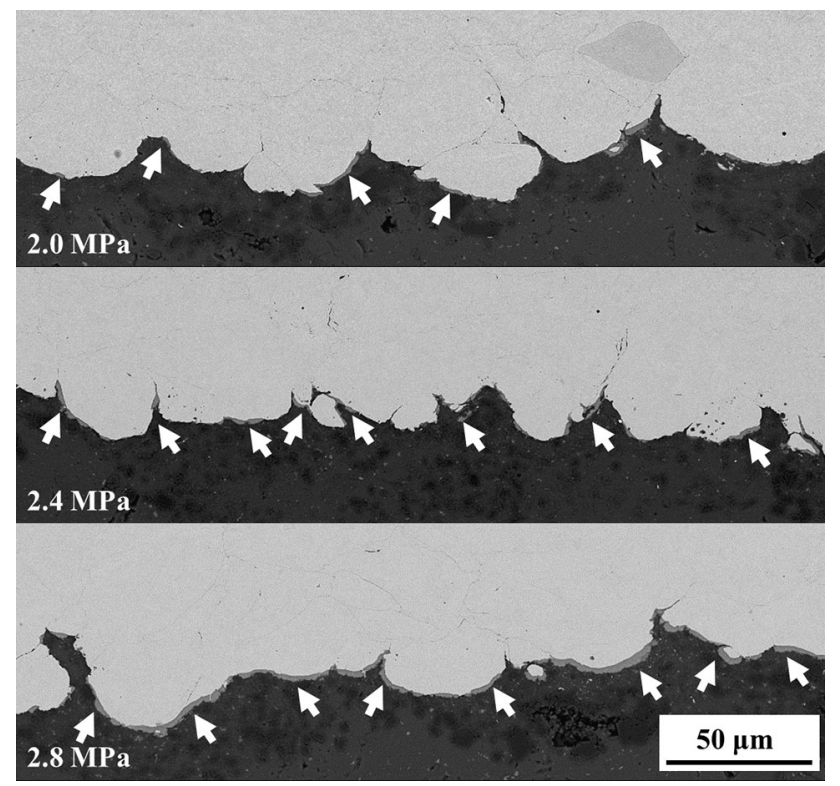

Fig. 7 Interfacial bonding features of $\mathrm{Ni}$ coating with different propelling gas pressures after heat treatment with diffusion layer marked by arrows metallurgical bonding due to the exposure of oxide-free surface (Ref 49, 50). In contrast, no such diffusion zone was formed at the interfaces between splat and substrate after heat treatment [see Fig. 3(d), (e) and (f)] even at extremely high parameters (3.7 MPa, $600{ }^{\circ} \mathrm{C}$, in Fig. 9). In other words, such high propelling gas pressure cannot directly lead to the formation of metallurgical bonding for a single splat between $\mathrm{Ni}$ and $\mathrm{Al}$. The successful deposition of single $\mathrm{Ni}$ particle onto the relatively soft $\mathrm{Al}$ substrate is mainly due to the mechanical interlocking.

\section{Adhesive Strength}

Figure 10 shows that the adhesion strength increases as a function of the propelling gas pressure. It implies that the strengthened peening effect at higher propelling gas pressure can enhance the particle cohesion by promoting the metallurgical bonding and result in a higher coating bonding strength. The combination of these factors may explain the reason for the improved adhesion strength and decreased porosity of cold-sprayed $\mathrm{Ni}$ coating on $\mathrm{Al}$ substrate at a higher propelling gas. Similar results about the peening effect on coating porosity were reported by Luo (Ref 39), which uses different contents of shot-peening particles in the $\mathrm{Ti}$ and Ti6Al4V powders. However, the effect of peening effect on the bonding strength in cold spray was not mentioned in their work (Ref 39$)$, which is an important factor to evaluate the coating properties in various applications including additive manufacturing. Besides, the existed deviation of measured adhesion strength values can be considered as a result of inherited defects as shown in Fig. 5.
Fig. $8 \mathrm{Ni}$-Al diffusion zone at the interfacial region of full coating fabricated at the propelling gas of $2.8 \mathrm{MPa}$
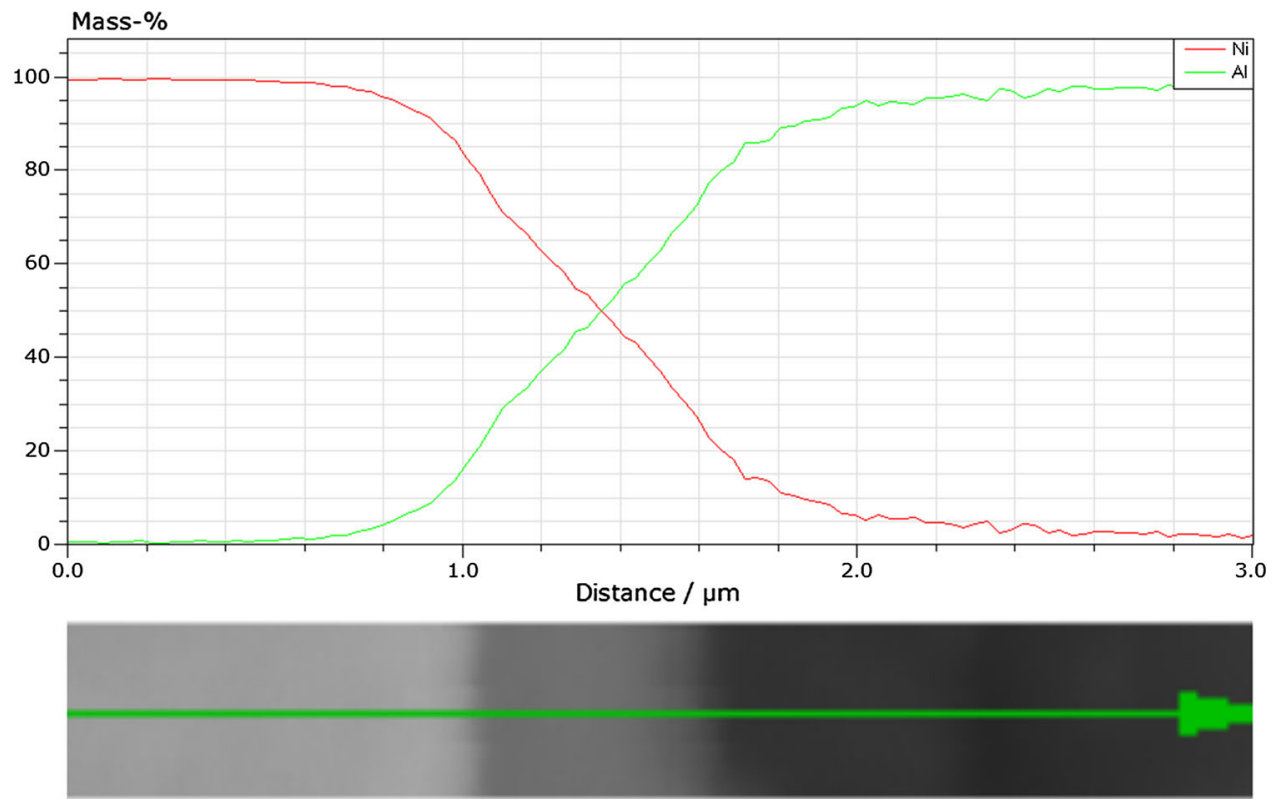


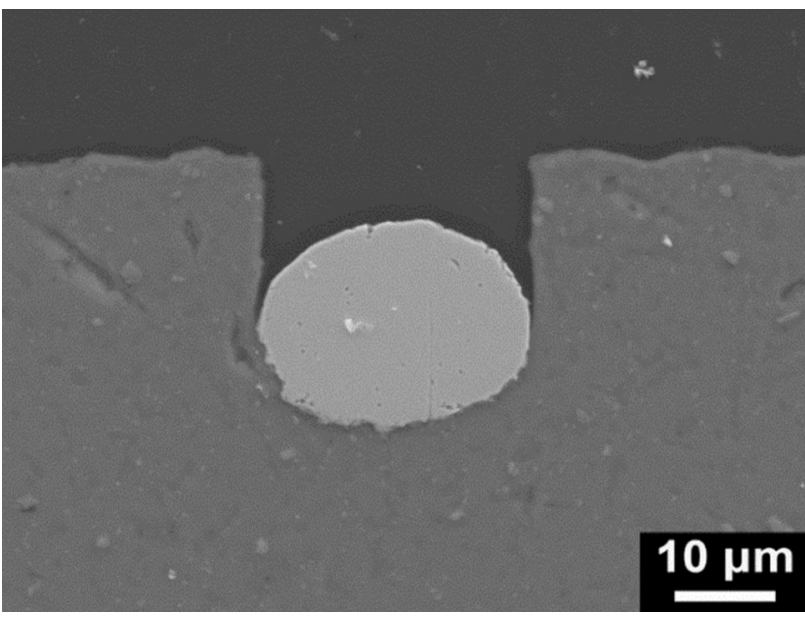

Fig. 9 Cross-sectional morphology of a single Ni splat after heat treatment at propelling gas of $3.7 \mathrm{MPa}$

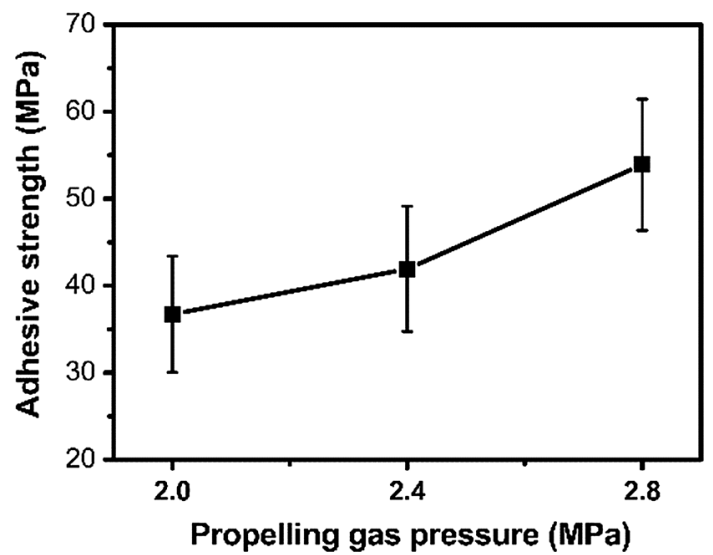

Fig. 10 Adhesive strength as a function of propelling gas pressures

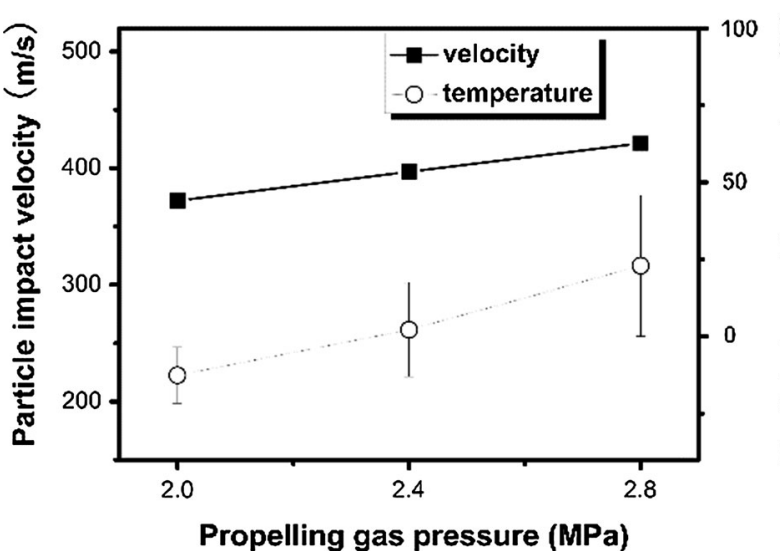

Fig. 11 Simulation results of particle velocity and temperature as a function of propelling gas pressures

\section{Finite Element Analysis of Coating Formation}

Firstly, the velocity and temperature of $\mathrm{Ni}$ particle prior to the impact onto the substrate were calculated by the proposed CFD model. As shown in Fig. 11, it is found that the propelling gas pressure significantly affects particle velocity and temperature. As the propelling gas pressure gradually increases, both particle impact temperature and velocity increase, which could facilitate the deposition of cold-sprayed coating. Higher propelling gas pressure not only improves the particle impact velocity, but also leads to a higher impact temperature. Particularly, the particle impact temperature is below $0{ }^{\circ} \mathrm{C}$ at the propelling gas pressure of $2.0 \mathrm{MPa}$. When the pressure increases to $2.8 \mathrm{MPa}$, the corresponding particle impact temperature is about $23{ }^{\circ} \mathrm{C}$.

Two-layer particle impact process was modeled by the Eulerian algorithm in Abaqus. Figures 12 and 13 show the distributions of effective plastic strain (PEEQ) and temperature after the impact of two-layer particles under different propelling gas pressures. Overall, a relatively low effective plastic strain (PEEQ) and a resultant low temperature of the deformed particles can be seen at a low propelling gas pressure of 2.0 MPa. As a general understanding (Ref 51), insufficient particle velocity below critical value cannot lead to the formation of strong bonds. As the pressure increased, the particles were more severely deformed due to the higher impact velocity. The ASI that is enhanced by the higher impact velocity and the successive particle impacts leads to the higher plastic strain value at a higher propelling gas pressure, as shown in Fig. 12(b) and (c). At the same time, due to the stronger plastic deformation, the higher temperature can be noticed between the deformed particles in Fig. 13 at a higher propelling gas pressure. The effect of the subsequent particle impact on the contact pressure between particle and substrate is given in Fig. 14. It can be noticed that a higher contact pressure is resulted from a higher propelling gas pressure at two-layer particle impact model. It can be further argued that such contact pressure will be strengthened under the successive particle impact in real spray process. Such enhanced peening effect at higher propelling gas pressure will increase the plastic particle deformation and promote the breaking-up and extrusion of native oxide film at particle surface. Finally, such higher contact pressure will lead to strong metallurgical bonding by direct contact between fresh metals.

\section{Discussion}

Although the term of peening effect or tamping effect in cold spray has been proposed for a long time, most of the studies focused on its effect on coating porosity and microstructure (Ref 36, 39). No attention was drawn on the influence of peening effect on adhesion strength of a coldsprayed coating. Many results based on TEM observation 
Fig. 12 Effective plastic strain evolution of two-layer $\mathrm{Ni}$ particle impact onto $\mathrm{Al}$ substrate at different propelling gas pressures

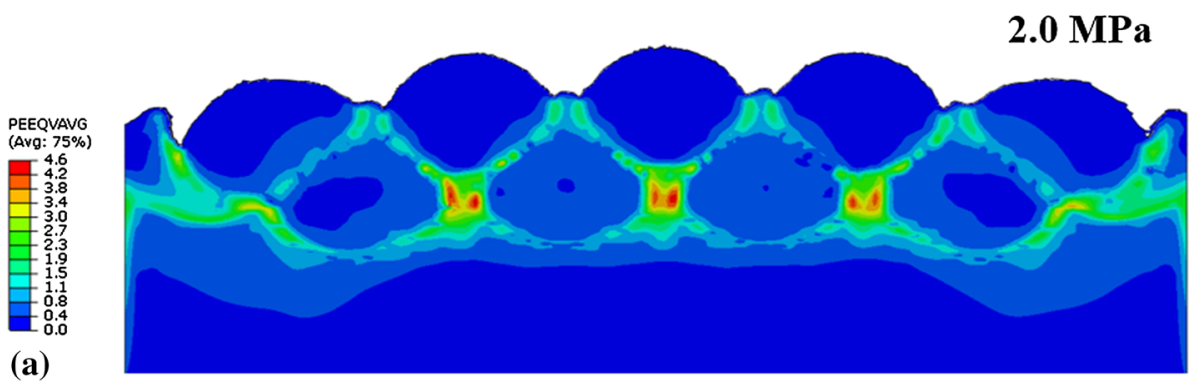

(a)

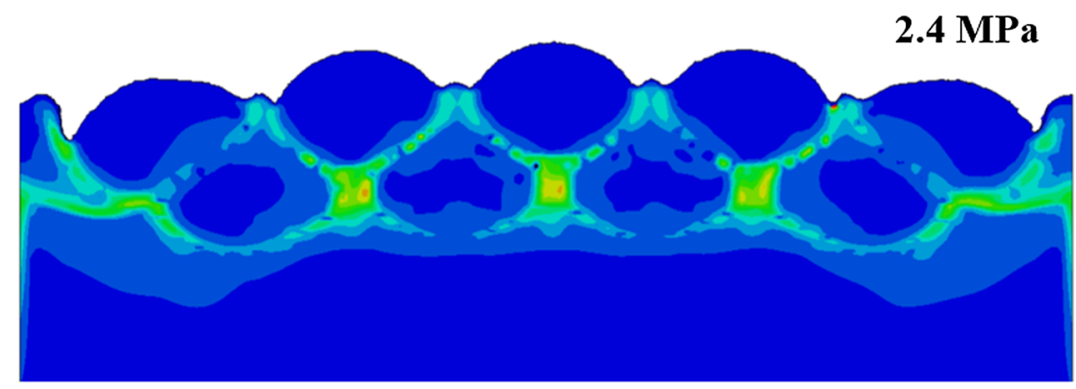

(b)

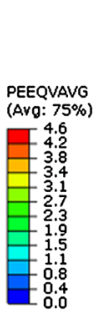

(c)

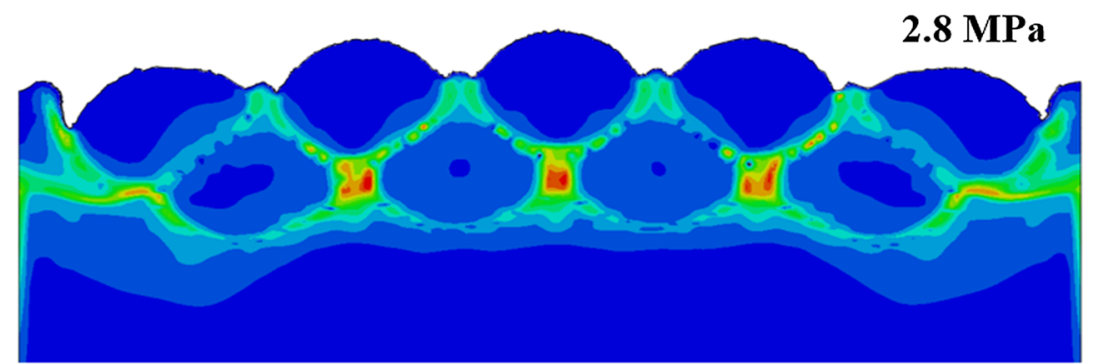

(Ref 52, 53) indicated that the existence of the interfacial defects such as microvoid and oxide film debris could inhibit the direct contact between the fresh metals of single particle and substrate and the formation of diffusion zone. Generally, an oxide-free Ni-Al interface is indispensable for the formation of diffusion zone during heat treatment, which allows the direct metal-to-metal contact for atomic diffusion. Accounting for the above findings of the bonding features of single-particle and full coating deposition, it may prudently suggest that the strengthened peening effect caused by the successive impact of particle is the determining factor for the formation of metallurgical bonding during full coating deposition.

During the high-velocity impact, the oxide films originally existing on the particle and substrate surfaces are disrupted, which results in the partial exposure of fresh metals of particle and substrate. With the continuous impact of subsequent particles, the oxide film debris is further broken up. Meanwhile, further deformation of deposited metal provides an opportunity for the fresh metal contact. Ultimately, the metallurgical bonding was generated under the consecutive high contact pressure due to the peening effect of subsequent particle impacts. As shown in
Fig. 3, the metallurgical bonding could not be formed directly between $\mathrm{Ni}$ splat and Al substrate due to insufficient kinetic energy of single Ni particles. However, for the full coating deposition (Fig. 7), massive impacts of subsequent particles with higher velocity at higher propelling gas pressure can provide more kinetic energy to promote the formation of metallurgical bonding. Such strengthened peening effect can significantly increase the area of metallurgical bonding between coating and substrate and result in a stronger metallurgical bonding inside the coating. Such promoted plastic deformation of $\mathrm{Ni}$ particle can also explain the decreasing coating porosity at higher propelling gas pressure (see Fig. 6). The strengthened peening effect significantly improves the coating bonding strength (Fig. 10). Thus, it is able to convince that this point of view about the strengthened peening effect at higher propelling gas pressure can provide a new direction to improve the coating properties by cold spray additive manufacturing. For example, it is possible to improve significantly the bonding strength and densification rate of a cold-sprayed sample by using situ shot peening, which may break through the bottleneck of the development of cold spray equipment. 
Fig. 13 Temperature evolution of two-layer Ni particle impact onto $\mathrm{Al}$ substrate at different propelling gas pressures

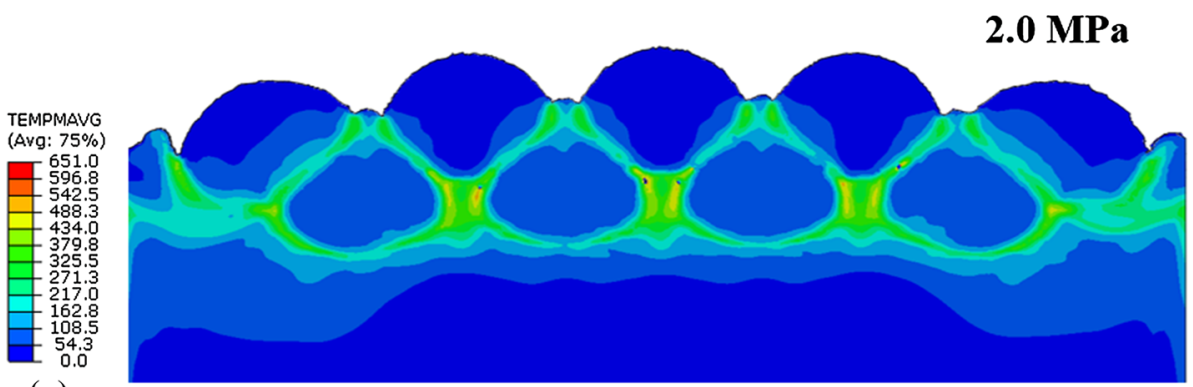

(a)

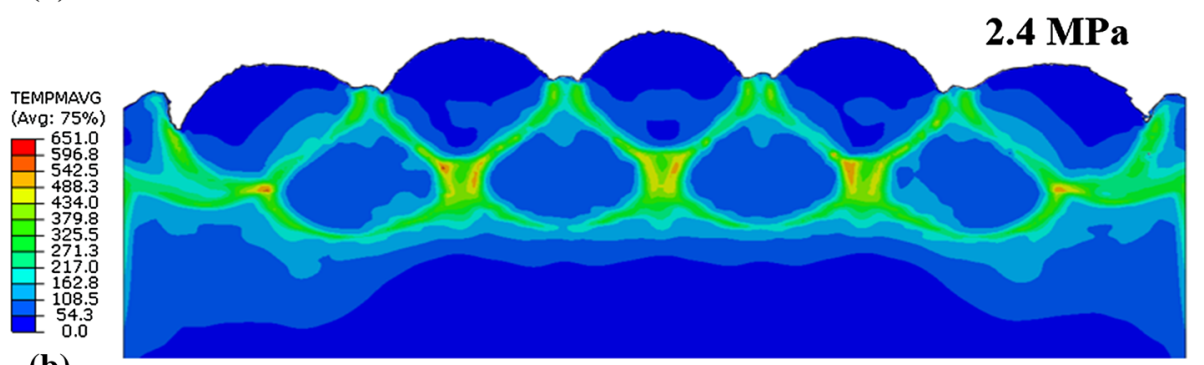

(b)

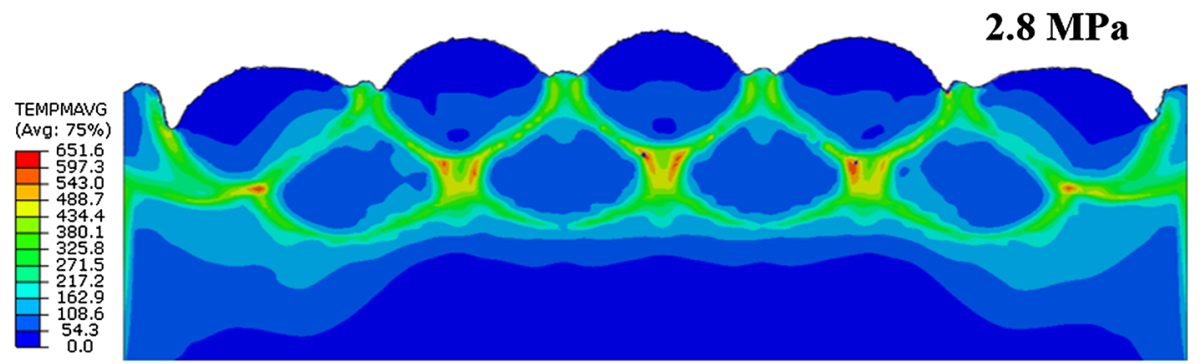

(c)

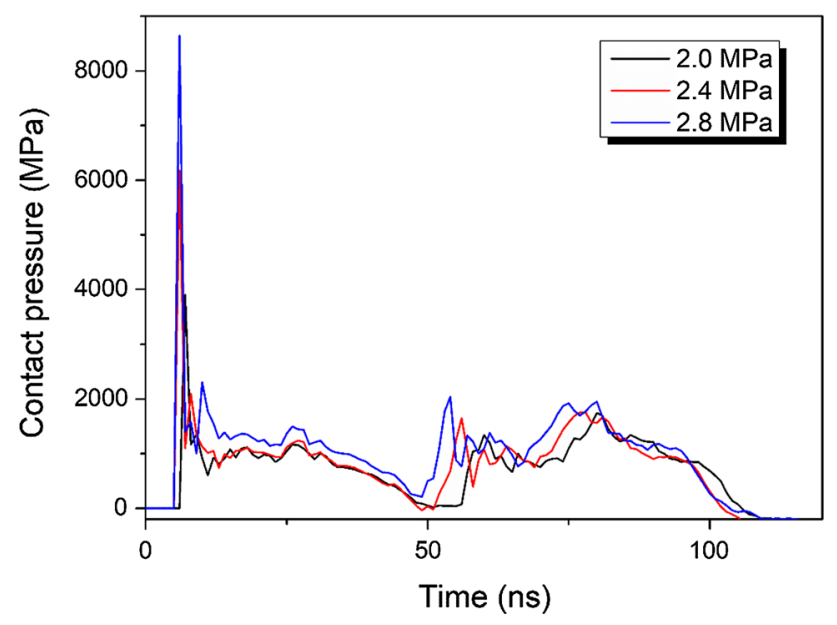

Fig. 14 Contact pressure evolution between coating and substrate during impact at different propelling gas pressures

\section{Conclusions}

In this paper, cold-sprayed $\mathrm{Ni}$ coating and individual splats were deposited on $\mathrm{Al}$ substrate with different propelling gas pressures. Heat treatment results show that metallurgical bonding generated only at the interface of coating deposition instead of the one of single splat even at a high spray parameter $\left(3.7 \mathrm{MPa}, 600{ }^{\circ} \mathrm{C}\right)$. Meanwhile, the results of $\mathrm{Ni}$-Al diffusion zone indicated a more intensive metallurgical bonding increased at higher propelling gas pressure. It can be believed that the strengthened peening effect by the successive impacts of the particle with higher kinetic energy is beneficial for the formation of metallurgical bonding. Therefore, the increased bonding strength of coldsprayed Ni coating is the result of the combined effect of an increase in peening effect at a higher propelling gas pressure. It is worth mentioning that the strengthened peening effect may help improve the bonding strength and decrease the porosity of cold-sprayed coating.

Acknowledgments The authors would like to acknowledge the supports by GDAS' Project of Science and Technology Development (Grants No. 2018GDASCX-0945), Natural Science Foundation of Guangdong Province (Grants No. 2018A0303130075), International Cooperation Project (Grants No. 201807010013) and High-level Leading Talent Introduction Program of GDAS (Grants No. 2016GDASRC-0204). As one of the authors, Chaoyue CHEN would like to acknowledge the supports by Joint Funds of the National Natural Science Foundation of China (Nos. U1560202 and 51690162, 51604171), the Shanghai Municipal Science and Technology Commission Grant (No. 17JC1400602), and the National Science and 
Technology Major Project "Aeroengine and Gas Turbine” (2017-VII0008-0102).

\section{References}

1. I. Gibson, D.W. Rosen, and B. Stucker, Additive Manufacturing Technologies, Springer, Berlin, 2010

2. T. DebRoy, H.L. Wei, J.S. Zuback, T. Mukherjee, J.W. Elmer, J.O. Milewski, A.M. Beese, A. Wilson-Heid, A. De, and W. Zhang, Additive Manufacturing of Metallic Components: Process, Structure and Properties, Prog. Mater Sci., 2018, 92(Supplement C), p 112-224

3. X. Yan, S. Yin, C. Chen, C. Huang, R. Bolot, R. Lupoi, M. Kuang, W. Ma, C. Coddet, H. Liao, and M. Liu, Effect of Heat Treatment on the Phase Transformation and Mechanical Properties of Ti6Al4V Fabricated by Selective Laser Melting, $J$. Alloys Compd., 2018, 764, p 1056-1071

4. A. Yuksel and M. Cullinan, Modeling of Nanoparticle Agglomeration and Powder Bed Formation in Microscale Selective Laser Sintering Systems, Addit. Manuf., 2016, 12, p 204-215

5. E. Tiferet, O. Rivin, M. Ganor, H. Ettedgui, O. Ozeri, E.N. Caspi, and O. Yeheskel, Structural Investigation of Selective Laser Melting and Electron Beam Melting of Ti-6Al-4V Using Neutron Diffraction, Addit. Manuf., 2016, 10, p 43-46

6. H. Assadi, F. Gartner, T. Stoltenhoff, and H. Kreye, Bonding Mechanism in Cold Gas Spraying, Acta Mater., 2003, 51(15), p 4379-4394

7. S. Yin, X. Wang, X. Suo, H. Liao, Z. Guo, W. Li, and C. Coddet, Deposition Behavior of Thermally Softened Copper Particles in Cold Spraying, Acta Mater., 2013, 61(14), p 5105-5118

8. S. Yin, M. Meyer, W. Li, H. Liao, and R. Lupoi, Gas Flow, Particle Acceleration, and Heat Transfer in Cold Spray: A Review, J. Therm. Spray Technol., 2016, 25(5), p 874-896

9. M. Grujicic, J. Saylor, D. Beasley, W. DeRosset, and D. Helfritch, Computational Analysis of the Interfacial Bonding Between Feed-Powder Particles and the Substrate in the ColdGas Dynamic-Spray Process, Appl. Surf. Sci., 2003, 219(3), p 211-227

10. C. Chen, Y. Xie, S. Yin, M.-P. Planche, S. Deng, R. Lupoi, and $\mathrm{H}$. Liao, Evaluation of the Interfacial Bonding Between Particles and Substrate in Angular Cold Spray, Mater. Lett., 2016, 173, p 76-79

11. C. Huang, W. Li, Y. Feng, Y. Xie, M.-P. Planche, H. Liao, and G. Montavon, Microstructural Evolution and Mechanical Properties Enhancement of a Cold-Sprayed $\mathrm{Cu} \mathrm{Zn}$ Alloy Coating with Friction Stir Processing, Mater. Charact., 2017, 125, p 76-82

12. C. Chen, X. Xie, Y. Xie, M.-P. Planche, S. Deng, G. Ji, E. Aubry, Z. Ren, and H. Liao, Cold Spraying of Thermally Softened NiCoated FeSiAl Composite Powder: Microstructure Characterization, Tribological Performance and Magnetic Property, Mater. Des., 2018, 160, p 270-283

13. M. Yu, X.K. Suo, W.Y. Li, Y.Y. Wang, and H.L. Liao, Microstructure, Mechanical Property and Wear Performance of Cold Sprayed Al5056/SiCp Composite Coatings: Effect of Reinforcement Content, Appl. Surf. Sci., 2014, 289, p 188-196

14. S. Yin, Y. Xie, J. Cizek, E.J. Ekoi, T. Hussain, D.P. Dowling, and R. Lupoi, Advanced Diamond-Reinforced Metal Matrix Composites via Cold Spray: Properties and Deposition Mechanism, Compos. B, 2017, 113, p 44-54

15. J. Pattison, S. Celotto, R. Morgan, M. Bray, and W. O'Neill, Cold Gas Dynamic Manufacturing: A Non-thermal Approach to Freeform Fabrication, Int. J. Mach. Tool Manuf., 2007, 47(3-4), p 627-634
16. S. Yin, P. Cavaliere, B. Aldwell, R. Jenkins, H. Liao, W. Li, and R. Lupoi, Cold Spray Additive Manufacturing and Repair: Fundamentals and Applications, Addit. Manuf., 2018, 21, p 628-650

17. C. Chen, S. Gojon, Y. Xie, Y. Shuo, C. Verdy, Z. Ren, H. Liao, and S. Deng, A Novel Spiral Trajectory for Damage Component Recovery with Cold Spray, Surf. Coat. Technol., 2016, 309, p 719-728

18. M. Hassani-Gangaraj, D. Veysset, V.K. Champagne, K.A. Nelson, and C.A. Schuh, Adiabatic Shear Instability is not Necessary for Adhesion in Cold Spray, Acta Mater., 2018, 158, p 430-439

19. Y. Ichikawa, R. Tokoro, M. Tanno, and K. Ogawa, Elucidation of Cold-Spray Deposition Mechanism by Auger Electron Spectroscopic Evaluation of Bonding Interface Oxide Film, Acta Mater., 2019, 164, p 39-49

20. H. Assadi, F. Gärtner, T. Stoltenhoff, and H. Kreye, Bonding Mechanism in Cold Gas Spraying, Acta Mater., 2003, 51(15), p 4379-4394

21. M. Grujicic, C.L. Zhao, C. Tong, W.S. DeRosset, and D. Helfritch, Analysis of the Impact Velocity of Powder Particles in the Cold-Gas Dynamic-Spray Process, Mater. Sci. Eng. A, 2004, 368(1-2), p 222-230

22. M. Grujicic, J.R. Saylor, D.E. Beasley, W.S. DeRosset, and D. Helfritch, Computational Analysis of the Interfacial Bonding Between Feed-Powder Particles and the Substrate in the ColdGas Dynamic-Spray Process, Appl. Surf. Sci., 2003, 219(3-4), p 211-227

23. Y. Xie, M.-P. Planche, R. Raoelison, H. Liao, X. Suo, and P. Hervé, Effect of Substrate Preheating on Adhesive Strength of SS 316L Cold Spray Coatings, J. Therm. Spray Technol., 2015, 25(12), p 123-130

24. X. Wang, F. Feng, M.A. Klecka, M.D. Mordasky, J.K. Garofano, T. El-Wardany, A. Nardi, and V.K. Champagne, Characterization and Modeling of the Bonding Process in Cold Spray Additive Manufacturing, Addit. Manuf, 2015, 8, p 149-162

25. G. Bae, Y. Xiong, S. Kumar, K. Kang, and C. Lee, General Aspects of Interface Bonding in Kinetic Sprayed Coatings, Acta Mater., 2008, 56(17), p 4858-4868

26. C. Chen, Y. Xie, R. Huang, S. Deng, Z. Ren, and H. Liao, On the Role of Oxide Film's Cleaning Effect into the Metallurgical Bonding During Cold Spray, Mater. Lett., 2018, 210(1), p 199202

27. L. Ajdelsztajn, A. Zúñiga, B. Jodoin, and E.J. Lavernia, Cold Gas Dynamic Spraying of a High Temperature Al Alloy, Surf. Coat. Technol., 2006, 201(6), p 2109-2116

28. T.S. Price, P.H. Shipway, D.G. McCartney, E. Calla, and D. Zhang, A Method for Characterizing the Degree of Inter-particle Bond Formation in Cold Sprayed Coatings, J. Therm. Spray Technol., 2007, 16(4), p 566-570

29. G. Bae, S. Kumar, S. Yoon, K. Kang, H. Na, H.-J. Kim, and C. Lee, Bonding Features and Associated Mechanisms in Kinetic Sprayed Titanium Coatings, Acta Mater., 2009, 57(19), p 56545666

30. M. Grujicic, C.L. Zhao, W.S. DeRosset, and D. Helfritch, Adiabatic Shear Instability Based Mechanism for Particles/Substrate Bonding in the Cold-Gas Dynamic-Spray Process, Mater. Des., 2004, 25(8), p 681-688

31. S. Yin, X.-F. Wang, W.Y. Li, and H.-E. Jie, Effect of Substrate Hardness on the Deformation Behavior of Subsequently Incident Particles in Cold Spraying, Appl. Surf. Sci., 2011, 257(17), p 7560-7565

32. X.-T. Luo, C.-X. Li, F.-L. Shang, G.-J. Yang, Y.-Y. Wang, and C.-J. Li, High Velocity Impact Induced Microstructure Evolution During Deposition of Cold Spray Coatings: A Review, Surf. Coat. Technol., 2014, 254, p 11-20

33. K. Kim, W. Li, and X. Guo, Detection of Oxygen at the Interface and Its Effect on Strain, Stress, and Temperature at the Interface 
Between Cold Sprayed Aluminum and Steel Substrate, Appl. Surf. Sci., 2015, 357, p 1720-1726

34. W.-Y. Li, C. Zhang, X. Guo, C.-J. Li, H. Liao, and C. Coddet, Study on Impact Fusion at Particle Interfaces and Its Effect on Coating Microstructure in Cold Spraying, Appl. Surf. Sci., 2007, 254(2), p 517-526

35. W.-Y. Li, C.-J. Li, and G.-J. Yang, Effect of Impact-Induced Melting on Interface Microstructure and Bonding of ColdSprayed Zinc Coating, Appl. Surf. Sci., 2010, 257(5), p 15161523

36. C.J. Li and W.Y. Li, Deposition Characteristics of Titanium Coating in Cold Spraying, Surf. Coat. Technol., 2003, 167(2-3), p 278-283

37. M.A. Klecka, and A.T. Nardi, Self-peening feedstock materials for cold spray deposition, Google Patents, 2016.

38. A.T. Nardi, T.I. El-Wardany, W. Werkheiser, and M.A. Klecka, Method for enhancing bond strength through in situ peening, 2016.

39. X.-T. Luo, Y.-K. Wei, Y. Wang, and C.-J. Li, Microstructure and Mechanical Property of Ti and Ti6Al4V Prepared by an In Situ Shot Peening Assisted Cold Spraying, Mater. Des., 2015, 85, p 527-533

40. Y.-K. Wei, X.-T. Luo, C.-X. Li, and C.-J. Li, Optimization of InSitu Shot-Peening-Assisted Cold Spraying Parameters for Full Corrosion Protection of $\mathrm{Mg}$ Alloy by Fully Dense Al-Based Alloy Coating, J. Therm. Spray Technol., 2017, 26(1), p 173-183

41. Y.-K. Wei, Y.-J. Li, Y. Zhang, X.-T. Luo, and C.-J. Li, Corrosion Resistant Nickel Coating with Strong Adhesion on AZ31B Magnesium Alloy Prepared by an In Situ Shot-Peening-Assisted Cold Spray, Corros. Sci., 2018, 138, p 105-115

42. Y. Xie, M.-P. Planche, R. Raoelison, P. Hervé, X. Suo, P. He, and H. Liao, Investigation on the Influence of Particle Preheating Temperature on Bonding of Cold-Sprayed Nickel Coatings, Surf. Coat. Technol., 2017, 318, p 99-105

43. G.R. Johnson, and W.H. Cook, A constitutive model and data for metals subjected to large strains, high strain rates and high temperatures, in Proceedings of the 7th International Symposium on Ballistics, The Hague, The Netherlands, 1983, pp. 541-547.
44. S. Yin, X.K. Suo, Y.C. Xie, W.Y. Li, R. Lupoi, and H.L. Liao, Effect of Substrate Temperature on Interfacial Bonding for Cold Spray of Ni onto Cu, J. Mater. Sci., 2015, 50(22), p 7448-7457

45. S. Yin, X. Wang, W. Li, H. Liao, and H. Jie, Deformation Behavior of the Oxide Film on the Surface of Cold Sprayed Powder Particle, Appl. Surf. Sci., 2012, 259, p 294-300

46. S. Yin, Y. Xie, X. Suo, H. Liao, and X. Wang, Interfacial Bonding Features of Ni Coating on Al Substrate with Different Surface Pretreatments in Cold Spray, Mater. Lett., 2015, 138, p 143-147

47. S. Guetta, M.H. Berger, F. Borit, V. Guipont, M. Jeandin, M. Boustie, Y. Ichikawa, K. Sakaguchi, and K. Ogawa, Influence of Particle Velocity on Adhesion of Cold-Sprayed Splats, J. Therm. Spray Technol., 2009, 18(3), p 331-342

48. H.-T. Wang, C.-J. Li, G.-J. Yang, and C.-X. Li, Cold Spraying of Fe/Al Powder Mixture: Coating Characteristics and Influence of Heat Treatment on the Phase Structure, Appl. Surf. Sci., 2008, 255(5, Part 1), p 2538-2544

49. I. Manna and J. Dutta Majumdar, Enhanced Kinetics of Diffusion Coating of Aluminium on Copper by Boundary Diffusion, $J$. Mater. Sci. Lett., 1993, 12(12), p 920-922

50. T. Price, P. Shipway, D. McCartney, E. Calla, and D. Zhang, A Method for Characterizing the Degree of Inter-particle Bond Formation in Cold Sprayed Coatings, J. Therm. Spray Technol., 2007, 16(4), p 566-570

51. C.J. Li, W.Y. Li, and H.L. Liao, Examination of the Critical Velocity for Deposition of Particles in Cold Spraying, J. Therm. Spray Technol., 2006, 15(2), p 212-222

52. K. Balani, A. Agarwal, S. Seal, and J. Karthikeyan, Transmission Electron Microscopy of Cold Sprayed 1100 Aluminum Coating, Scr. Mater., 2005, 53(7), p 845-850

53. C. Borchers, F. Gärtner, T. Stoltenhoff, and H. Kreye, Microstructural Bonding Features of Cold Sprayed Face Centered Cubic Metals, J. Appl. Phys., 2004, 96(8), p 4288

Publisher's Note Springer Nature remains neutral with regard to jurisdictional claims in published maps and institutional affiliations. 